\title{
Cyclic polyesters prepared by poly(oxypropylene oxymaloyl) ring-chain reactions
}

\author{
M. I. Ferrahi*, M. Belbachir \\ Laboratoire de Chimie des Polymères, Département de Chimie, Faculté des Sciences, Université d'Oran Es-Sènia BP N \\ 1524 El M’Naouar, 31000 Oran Algerie
}

Received 17 October 2006; accepted in revised form 11 December 2006

\begin{abstract}
The synthesis of cyclic polyesters of poly(oxypropylene oxymaloyl) from a ring-chain reaction was carried out at $40^{\circ} \mathrm{C}$ with 'Maghnite' an acid exchanged montmorillonite as acid solid ecocatalyst $\left(\mathrm{Mag}-\mathrm{H}^{+}\right)$. 'Maghnite' is already used as catalyst for polymerization of many vinylic and heterocyclic monomers [1]. The effect of amount of catalyst on yield and molecular weight of polymer was studied.

A typical reaction product was analyzed by gel permeation chromatography (GPC) as well as by nuclear magnetic resonance spectroscopy $\left({ }^{1} \mathrm{H}-\mathrm{NMR}\right)$ and the existence of cyclic species was proven.
\end{abstract}

Keywords: polymer synthesis, molecular engineering, maleic anhydride, maghnite, montmorillonite, oxypropylene

\section{Introduction}

As clay catalysts, montmorillonites a class of inexpensive and non-corrosive solid acids, have been used as efficient catalysts for organic reactions. Montmorillonite catalysts are easily recovered and reused [2-8]. In continuation of our studies on environmentally bening methods using solid supports, we report that acid-exchanged montmoril-

n

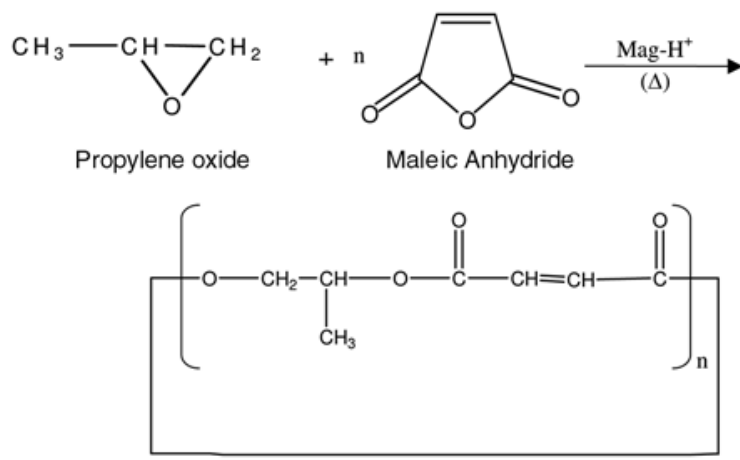

Figure 1. Synthesis of Cyclo Poly(oxypropylene oxymaloyl) by Mag- $\mathrm{H}^{+}$catalyst

*Corresponding author, e-mail: mohammed.ferrahi@caramail.com (C) BME-PT and GTE lonite $\left(\mathrm{Mag}-\mathrm{H}^{+}\right)$is a novel, efficient solid catalyst for the synthesis of cyclic polyesters from ringchain reaction of poly(oxypropylene oxymaloyl) 'Figure 1'.

In contrast to the more usually used catalyst, Mag $-\mathrm{H}^{+}$can be easily separated from the polymer and regenerated by heating to a temperature above $100^{\circ} \mathrm{C}$. The effect of the relative amounts of Mag $-\mathrm{H}^{+}$was discussed.

\section{Experimental}

\subsection{Materials}

1) 'Maghnite- $\mathrm{H}^{+} 0.25 \mathrm{M}$ ': The preparation of the Mag-H was carried out by using a method similar to that described by Belbachir and al. [1]. Indeed, the raw-Maghnite $(20 \mathrm{~g})$ was crushed for $20 \mathrm{~min}$ using a Prolabo ceramic balls grinder. It was then dried by baking at $105^{\circ} \mathrm{C}$ for $2 \mathrm{~h}$. The Maghnite was then weighed and placed in an Erlenmeyer flask together with $500 \mathrm{ml}$ of distilled water. The 
Maghnite/water mixture was stirred using a magnetic stirrer and combined with sulfuric acid, until saturation was achieved over 2 days at room temperature, the mineral was washed with water until it became sulfate free and then dried at $150^{\circ} \mathrm{C}$.

The concentration $0.25 \mathrm{M}$ of sulfuric acid treatment solution was used to prepare 'Maghnite- $\mathrm{H}^{+}$ $0.25 \mathrm{M}^{\prime}$.

2) Propylene oxide (99\%), Maleic anhydride (99\%), Ethanol (99\%) and Acetone (99\%) were used as received.

\subsection{Procedure and Polymer characterization}

Polymerizations were carried out in stirred flasks at $40^{\circ} \mathrm{C}$. The catalyst was dried in a muffle at $120^{\circ} \mathrm{C}$ over night and then transferred to a vacuum desiccator containing $\mathrm{P}_{2} \mathrm{O}_{5}$. After cooling to room temperature under vacuum, the mineral was added to the Propylene oxide $(10.85 \mathrm{~mol} / \mathrm{l})$, Maleic anhydride $(8.54 \mathrm{~mol} / \mathrm{l})$ mixture preliminary kept in stirred flask at $40^{\circ} \mathrm{C}$. At the required time, an aliquot of the reaction mixture was then taken in such manner as to exclude any clay mineral and slowly added to ethanol with stirring. The precipitated polymer was filtered off and dried under vacuum and weighed. The polymers were redissolved in acetone and precipitated into ethanol for characterization and molecular weight measurement.

Molecular weights were determined by a Waters high pressure GPC instrument (Model 6000A Pump) having a serie of ultra-Styragel columns (100, 500, 103, 104, $105 \AA$ A), a Differential Refractometer 2401 and a UV absorbance Detector Model 440. The flow rate of tetrahydrofuran (THF) was $1 \mathrm{ml} / \mathrm{min}$. The calibration curve was made with well-fractionated Poly(oxybutylene oxymaleoyl) standards.

${ }^{1} \mathrm{H}-\mathrm{NMR}$ spectra were recorded on an AM $300 \mathrm{FT}$ Bruker instrument using deuterated acetone as solvent, and tetramethylsilane (TMS) as internal standard.

\section{Results and Discussion}

\subsection{Polymerization and Product Characterization}

The results of bulk polycondensation experiments of $10.85 \mathrm{M}$ Propylene oxide with $8.54 \mathrm{M}$ maleic anhydride induced by 'Maghnite- $\mathrm{H}^{+} 0.25 \mathrm{M}$ ' are
Table 1. Polycondensation of Propylene oxide with maleic anhydride induced by 'Maghnite- $\mathrm{H}^{+} 0.25 \mathrm{M}$ '

\begin{tabular}{|c|c|c|c|c|c|}
\hline Experiment & $\begin{array}{c}\text { 'Maghnite-H } \\
\text { 0.25M' [\%] }\end{array}$ & $\begin{array}{c}\text { Yield } \\
{[\%]}\end{array}$ & $\mathbf{M n}$ & $\mathbf{M}_{\mathbf{w}}$ & $\mathbf{M}_{\mathbf{w}} / \mathbf{M}_{\mathbf{n}}$ \\
\hline 1 & 15 & 50.2 & 549 & 1825 & 3.32 \\
\hline 2 & 10 & 42.7 & 641 & 2971 & 4.63 \\
\hline 3 & 5 & 31.5 & 735 & 3758 & 5.11 \\
\hline 4 & 2.5 & 17.2 & 823 & 4685 & 5.69 \\
\hline
\end{tabular}

reported in Table 1. For all these experiments the temperature was kept constant at $40^{\circ} \mathrm{C}$ for 6 hours.

\subsection{Effect of the amount of Mag-H on the polymerization}

We can see from Table 1 that the yield increases as the proportion of 'Maghnite- $\mathrm{H}^{+} 0.25 \mathrm{M}$ ' increases. However the molecular weight decreases (experiments 1, 2, 3, 4). Table 2 shows the effect of the amount of Mag- $\mathrm{H}$ on the polymerization yield. Indeed, using various amounts of Mag-H: 2.5, 5, 10 and $15 \%$ by weight, the polymerization was carried out in bulk at $40^{\circ} \mathrm{C}$. The polymerization yield increased with the amount of Mag-H, thus clearly showing the effect of Mag-H as a catalyst. This phenomenon is probably the result of an increase in the number of 'initiating active sites' responsible of inducing polymerization, a number that is prorata to the amount of catalyst used a reaction.

\subsection{Characterization of products}

An investigation was devoted to the analysis of the polymer from experiment 4 in Table 1 by $300 \mathrm{MHz}$ ${ }^{1} \mathrm{H}-\mathrm{NMR}$ spectroscopy (Figure 2).

According to the work published by Hamilton and Semlyen [9] and Vivas and Contreras [10] the $300 \mathrm{MHz}{ }^{1} \mathrm{H}-\mathrm{NMR}$ spectra (in deuterated acetone, Figure 2) showed four sets of peaks, corresponding to the methyl group at $1.45 \mathrm{ppm}$, the $\beta$ methylene

Table 2. Yields with time for $10.85 \mathrm{~mol} / \mathrm{L}$ of Propylene oxide, $8.54 \mathrm{~mol} / \mathrm{L}$ of maleic anhydride, the amounts of Maghnite- $\mathrm{H}^{+} 0.25 \mathrm{M}$ were: a) $2.5 \%$, b) $5 \%$, c) $10 \%$, d) $15 \%$

\begin{tabular}{|c|c|c|c|c|c|c|}
\hline \multirow{2}{*}{$\begin{array}{c}\text { Yields } \\
{[\%]}\end{array}$} & \multicolumn{7}{|c|}{ Time [hours] } \\
\cline { 2 - 7 } & $\mathbf{1}$ & $\mathbf{2}$ & $\mathbf{3}$ & $\mathbf{4}$ & $\mathbf{5}$ & $\mathbf{6}$ \\
\hline $\mathrm{a}$ & 8.5 & 10.8 & 12.7 & 13.5 & 15.2 & 17.2 \\
\hline $\mathrm{b}$ & 12.5 & 16.7 & 21.6 & 24.8 & 28.4 & 31.5 \\
\hline $\mathrm{c}$ & 21.7 & 24.5 & 28.7 & 32.8 & 37.2 & 42.7 \\
\hline $\mathrm{d}$ & 27.8 & 30.5 & 34.3 & 39.9 & 46.2 & 50.2 \\
\hline
\end{tabular}




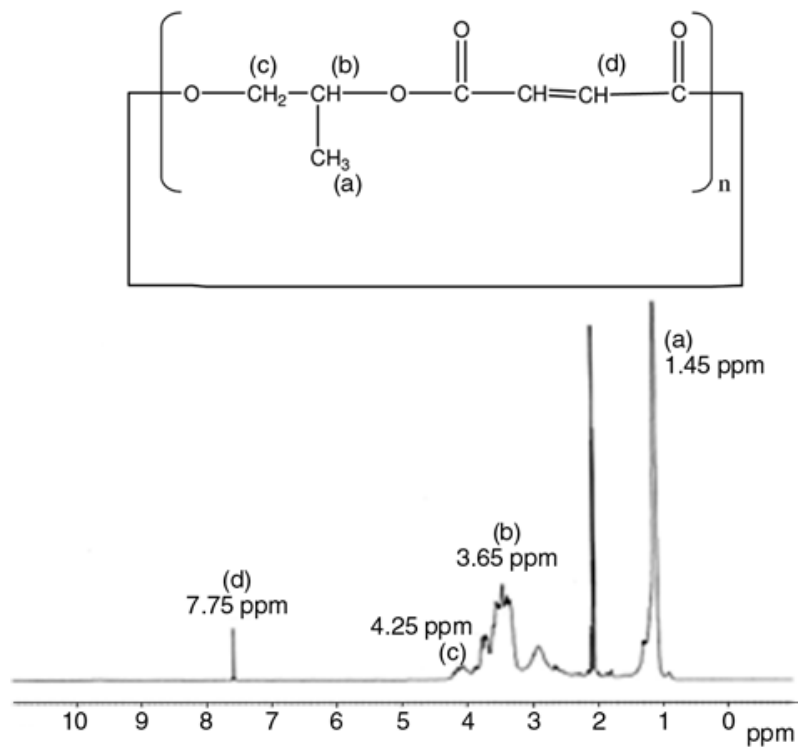

Figure 2. ${ }^{1} \mathrm{H}-\mathrm{NMR}$ spectra of the cyclic poly(oxypropylene oxymaloyl)product of experiment 4 in Table 1

groups at $3.65 \mathrm{ppm}$, the $\alpha$ methylene groups at $4.25 \mathrm{ppm}$, and the ethylene groups at $7.75 \mathrm{ppm}$, respectively.

\section{Conclusions}

The present work shows that the preparation of cyclic polyesters of poly(oxypropylene oxymaloyl) can be induced in heterogenous phase by proton exchanged montmorillonite clay called Maghnite $\left(\mathrm{Mag}-\mathrm{H}^{+}\right)$. The catalytic activity of this catalyst measured by the yield and the molecular weight of the formed polymer, depends on the proportion of catalyst in the reaction medium, cyclic polyesters of poly(oxypropylene oxymaloyl) was produced by a very simple procedure, just by filtering, the clay can be separated from the reaction mixture, and acidic clay is inexpensive, stable and non corrosive.

\section{References}

[1] Belbachir M., Bensaoula A.: Composition and method for catalysis using bentonites. US6274527, U.S.Patent (2001).

[2] Yahyaoui A., Belbachir M., Hachemaoui A.: Cationic polymerization of 1,2-epoxypropane by an acid exchanged montmorillonite clay in the presence of ethylene glycol. International Journal of Molecular Science, 4, 572-585 (2003).

[3] Ballantine J. A., Davies M., Purnell H.: Chemical yields using sheet silicates: novel interlamellar dehydrations of alcohols to ethers and polymers. Journal of Chemical Science. Chemistry Communications, 6, 427-428 (1981).

[4] Odian G.: Principles of polymerization. Wiley, New York (1991).

[5] Madejovà J., Bednànikovà E., Komadel P., Cicel, B.: in Proc. $11^{\text {th }}$ Conference of Chemistry, Miner and Petrol, Ceske Budéjovica 1990. Ed. J. Konta. Charles University, Prague, 267 (1993).

[6] Ferrahi M. I., Belbachir M.: Polycondensation of tetrahydrofuran with phthalic anhydride induced by a proton exchanged montmorillonite clay. International Journal of Molecular Science, 4, 312-325 (2003).

[7] Ferrahi M. I., Belbachir M.: Synthesis of cyclic polyesters of poly(oxybutylene oxymaleoyl). Journal of Polymer Research, 12, 167-171 (2005).

[8] Ferrahi M. I., Belbachir M.: Preparation of poly(oxybutyleneoxymaleoyl) catalyzed by a proton exchanged montmorillonite clay. Molecules, 9, 968- 977 (2004).

[9] Hamilton S. C., Semlyen J. A.: Cyclic polyesters: 5. Cyclics prepared by poly(decamethylene terephthalate) ring-chain reactions. Polymer, 38, 1685-1691 (1997).

[10] Vivas M., Contreras J.: Ring-opening polymerization of $\varepsilon$-caprolactone initiated by diphenylzinc. European Polymer Journal, 39, 43-47 (2003). 